\title{
The microspatial distribution of beetles (Coleoptera) on exposed riverine sediments (ERS)
}

\author{
AdAm J. BATES ${ }^{1}$, Jon P. SADLER ${ }^{1}$, Joe N. PERRY ${ }^{2}$ and Adrian P. FOWLES ${ }^{3}$ \\ ${ }^{1}$ School of Geography, Earth \& Environmental Sciences, The University of Birmingham, Edgbaston, Birmingham, \\ B15 2TT, UK; e-mail: a.j.bates@bham.ac.uk \\ ${ }^{2}$ Rothamstead Research, Harpenden, Hertfordshire, AL5 2JQ, UK \\ ${ }^{3}$ Countryside Council for Wales, Plas Penrhos, Bangor, Gwynedd, LL57 2LQ, UK
}

Key words. Carabidae, Elateridae, hydroecology, habitat preference, microdistribution, pitfall trapping, riparian, exposed riverine sediments, river Severn, Spatial Analysis by Distance Indices, (SADIE)

\begin{abstract}
Exposed Riverine Sediments (ERS) are often characterised by a high diversity of microhabitats due to strong lateral gradients in temperature, humidity, inundation frequency and availability of aquatic food resources and to variations in the degree of vegetation cover, sediment size and sorting. This variation, potentially in combination with interspecific competitive interactions, is thought to drive the microspatial distribution of ERS invertebrates. This research investigated the microspatial distribution of six ERS specialist beetles across three discreet patches of ERS. In particular it examined the temporal stability of species distributions, and their spatial association with environmental variability and other species. The research used a grid of 204 modified dry pitfall traps over six sampling periods in which weather conditions and water levels were stable, and used the Spatial Analysis by Distance IndicEs (SADIE) method to test the significance of spatial distributions and associations. Strong and significant microspatial zonation was observed for all species, and with few exceptions these distributions were remarkably stable across the study period. This zonation was mainly associated with elevation and proximity to the water, and several species were consistently spatially associated or disassociated with one another. This suggests that laterally more extensive patches of ERS support more species. Operations that reduce the size of ERS patches, such as channelisation, aggregate extraction and regulation are therefore likely to reduce ERS invertebrate diversity.
\end{abstract}

\section{INTRODUCTION}

Species typically show non-random, spatiotemporally heterogeneous distributions, which vary with the scale of observation (e.g. Levin, 1992; Dungan et al., 2002). At the microscale, the distribution and abundance patterns of a species are heavily influenced by the appraisal, decision-making, and movement responses of individuals to interacting physical and biotic factors (Hassell \& Southwood, 1978; Wallin \& Exbom, 1994; Gereben, 1995). Within a community, species demonstrate an array of potentially interacting distributions according to their competitive abilities and habitat preference, such that a mosaic of spatially distinct microspatial distributions results (e.g. Colombini et al., 1994; Ottesen, 1996).

Exposed riverine sediments (ERS) are areas of relatively unvegetated, alluvial, within-channel, silts, sands and gravels whose vertical distribution lies between the levels of bank-full and the typical base flow of a river. As such, they are situated within the aquatic terrestrial ecotone, which is characterised by a high diversity of microhabitats arranged along gradients of disturbance and succession (Ward et al., 1999). Within patches of ERS there are strong lateral gradients of temperature, humidity, inundation frequency and availability of aquatic food resources (Desender, 1989; Paetzold et al., 2005), superimposed onto which, can be variations in the degree of vegetation cover, sediment size and sorting, shading and trampling damage. The known movement responses of ERS specialist beetles to variation in sediment, moisture, cover, and light (Andersen, 1978, 1985, 1989) may explain their fairly consistent spatial association with particular microhabitats (c.f. Andersen, 1969, 1983, 1988; Desender, 1989).

This study investigates the stability of the microspatial distribution of ERS specialist beetles and their spatial association with environmental variables and inter-specifics during stable water level and weather conditions. It uses the Spatial Analysis by Distance IndicEs method (SADIE) (Perry, 1995; Perry et al., 1999; Perry \& Dixon, 2002) to test the statistical significance of perceived patterns of microspatial distribution and spatial association. Previous studies of riparian beetle microspatial distribution (e.g. Bonn \& Kleinwächter, 1999; Antvogel \& Bonn, 2001) used correlation and multi-variate techniques to identify the microhabitat affinity of a species, and, although valid, these methods do not fully use the available spatial information in the data.

Microspatial segregation of species can be caused by inter-specific competition, but this segregation alone does not necessarily demonstrate the existence of such competition (Hastings, 1987; Niemelä, 1993). Nonetheless, consistent microspatial separation of species draws attention to where such competitive interactions are likely to exist. At a whole-patch scale, ERS patches with a greater diver- 


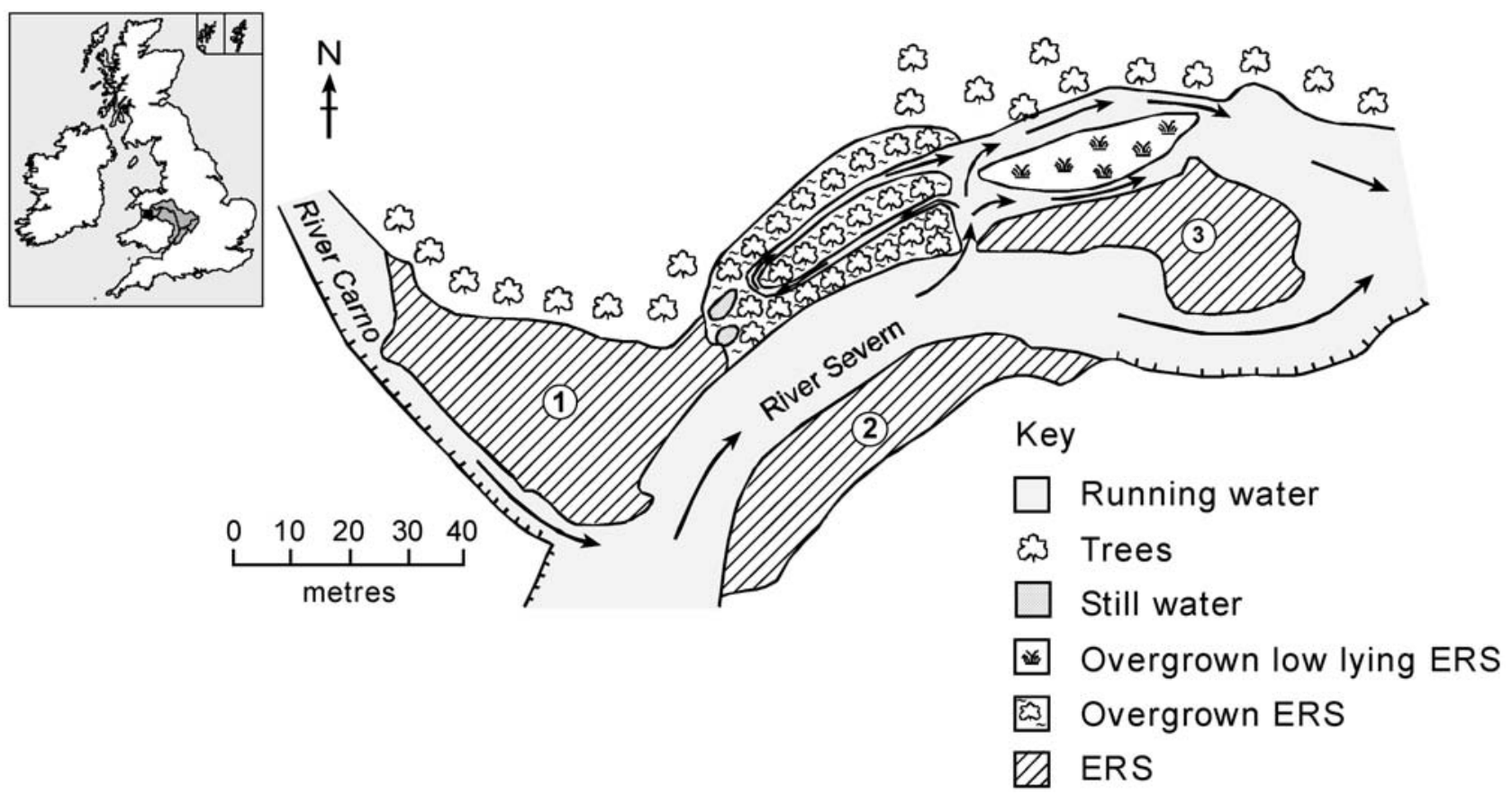

Fig. 1. Distribution of the study bars.

sity of microhabitats support more species rich assemblages that contain a larger number of rare and specialist species (Sadler et al., 2004). Increasing the understanding of diversity distribution, resource partitioning and competitive interactions at the microscale, should provide an essential insight into the processes maintaining community diversity and ecological function in ERS and riparian systems.

This research aimed to answer the following research questions: (1) Are there temporally stable microspatial patterns of species zonation that are consistent between local populations? (2) Do these patterns correlate with microhabitat variation? (3) Are species consistently microspatially aggregated or separated? (4) What are the implications for the conservation of species diversity in these habitats?

\section{MATERIAL AND METHODS}

\section{Site description}

The study site was within a regulated, but semi-natural "wandering gravel bed" section (sensu Church, 1983) of the River Severn $\left(3^{\circ} 25^{\prime} \mathrm{E}, 52^{\circ} 30^{\prime} \mathrm{N}\right)$, that is characterised by a high quality ERS beetle fauna in a UK context (Sadler et al., 2004). Three distinct patches of ERS (Fig. 1), which varied widely in their shape, size, sediment characteristics, degree of livestock trampling and elevation (Table 1), were studied.

\section{Environmental variables}

Sediment size distributions were estimated from 5-10, 0.25 $\mathrm{m}^{2}$ quadrats, in situ using a photographic technique (Petts et al., 2000; Bates et al., 2005). The percentage of fine sediments were estimated from the number of grid points within quadrats where sediments were $<8 \mathrm{~mm}$. This method was used to support field maps of areas of visibly dissimilar sediments and used in the analyses where appropriate (Bar 2).

The vegetation cover was estimated using the following scale: (1) bare/very sparse, (2) sparse, (3) light, (4) regular, (5) quite dense, (6) very dense. A digital elevation model of the study site was created using a Leica differential global positioning system, the edge of ERS patches, the position of traps, vegetation density and areas of similar sediments were all spatially referenced. This information was used to determine the environmental conditions around each trap.

Water stage data were taken from a gauging station $\sim 250 \mathrm{~m}$ downstream of the study site. Water levels that would flood traps caused by reservoir releases or rainfall were considered flow pulses (stage height of $>1.40 \mathrm{~m}$ ). Daily total rainfall and maximum and minimum temperature data were taken from sampling stations at Llandinam $\left(3^{\circ} 27^{\prime} \mathrm{E}, 52^{\circ} 29^{\prime} \mathrm{N}, 131 \mathrm{~m}\right.$ a.s.1., $\sim 2.5$ $\mathrm{km}$ from the study site) and Llanfair Caereinion $\left(3^{\circ} 16^{\prime} \mathrm{E}\right.$, $52^{\circ} 38^{\prime} \mathrm{N}, 243 \mathrm{~m}$ a.s.1., $\sim 28 \mathrm{~km}$ from the study site) respectively. Fig. 2 summarises changes in weather conditions and the timing of flow pulses in the fortnight preceding and during sampling. Although weather conditions and flow levels were stable during sampling, in-between these sampling events there was considerable variation. The flow pulse between 24-26/7/2003 was of

TABLE 1. Summary variables for the study bars.

\begin{tabular}{cccccccccc}
\hline $\begin{array}{c}\text { Bar } \\
\text { code }\end{array}$ & $\begin{array}{c}\text { Area } \\
\left(\mathrm{m}^{2}\right)\end{array}$ & $\begin{array}{c}\text { Total } \\
\text { traps }\end{array}$ & $\begin{array}{c}\text { Trap density } \\
\left(\mathrm{m}^{2}\right)\end{array}$ & $\begin{array}{c}\text { Typical sediment } \\
\text { size }(\mathrm{phi})\end{array}$ & $\begin{array}{c}\text { Vegetation } \\
\text { cover }(\%)\end{array}$ & $\begin{array}{c}\text { Heavily } \\
\text { trampled }\end{array}$ & $\begin{array}{c}\text { Sediment } \\
\text { zones }\end{array}$ & $\begin{array}{c}\text { Altitudinal } \\
\text { range }(\mathrm{m})\end{array}$ & $\begin{array}{c}\text { Total } \\
\text { abundance }\end{array}$ \\
\hline 1 & 1539.1 & 90 & 0.058 & -4.41 & 20 & no & no & 1.2 & 6603 \\
2 & 969.4 & 58 & 0.060 & -4.15 & 3 & yes & yes & 1.2 & 1218 \\
3 & 837.5 & 56 & 0.067 & -5.13 & 35 & no & no & 0.5 & 7497 \\
\hline
\end{tabular}




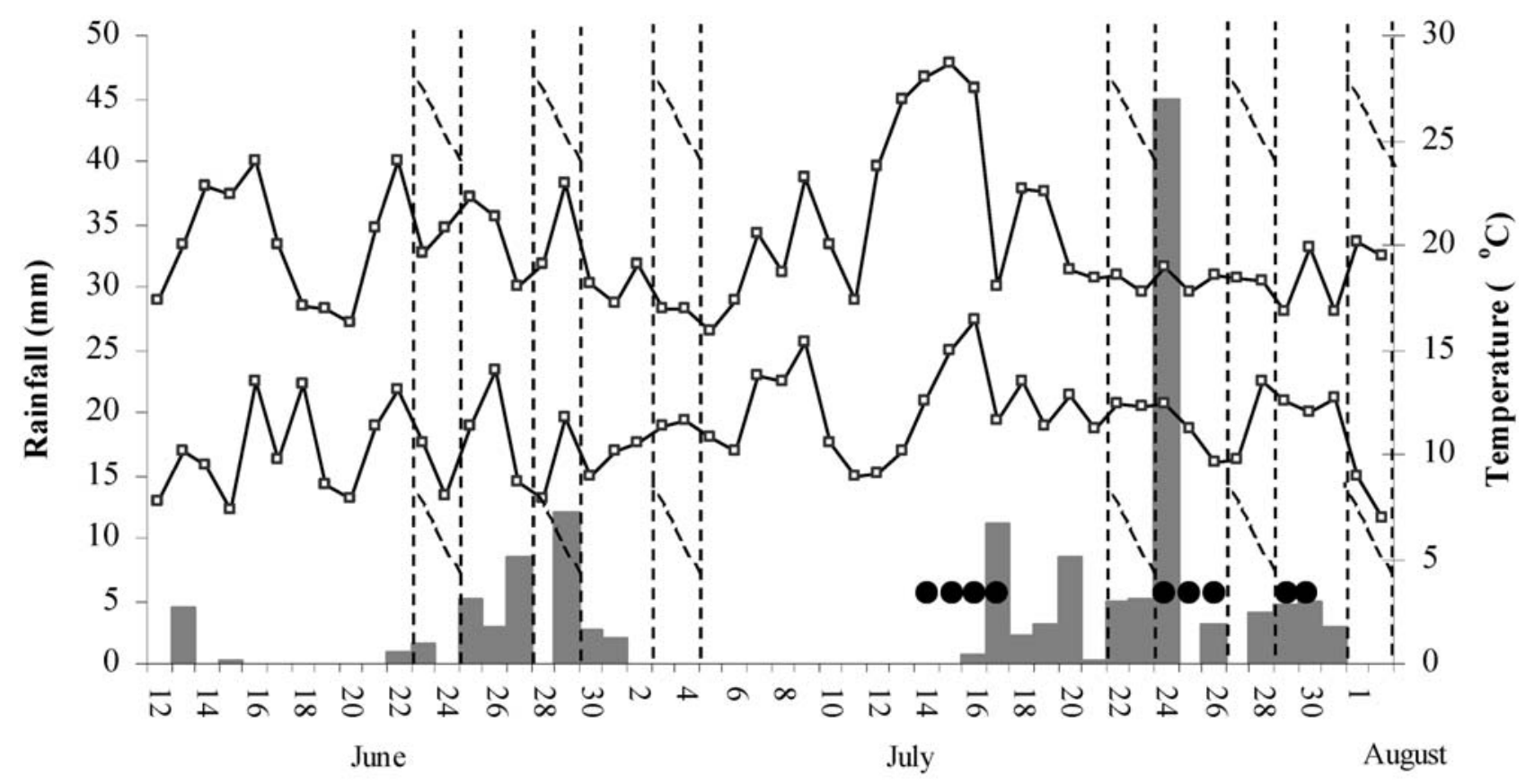

Date (2003)

Fig. 2. Flow pulse and weather data from the study period and ten preceding days. Grey bars are total daily rainfall (9:00 on the date displayed to 9:00 on the following date), the upper and lower line graphs are daily (9:00 to 9:00) maximum and minimum temperatures, black dots are flow pulses, and hatched bars are sampling periods.

particular importance as it was of sufficient magnitude to inundate large areas of the bars (nearly the whole of Bar 3).

\section{Trapping method}

Modified non-fatal pitfall traps were employed because the use of fatal traps at the necessary density would lead to unacceptably high rates of mortality, given the conservation importance of these sites. Some of the implications of using these traps are reviewed by Bates et al. (2005). An additional consideration was that individuals could be trapped several times on the same date, thereby altering the observed distribution patterns. However, only $0.55 \%$ of 687 individually marked Bembidion atrocaeruleum (Stephens, 1828) from a linked markrecapture study (Bates et al., 2006) were captured more than once on the same date, so this error was considered negligible.

\section{Sampling}

Grids of traps were set at 3-4 m intervals on each bar (Table 1 ), and rendered inactive between trapping periods using small polythene squares secured over the trap aperture with elastic bands. Traps were activated and emptied in the same sequence after $\sim 24 \mathrm{~h}$ on $23-24 / 6 / 2003,28-29 / 6 / 2003,3-4 / 7 / 2003$, $22-23 / 7 / 2003,27-28 / 7 / 2003$ and $1-2 / 8 / 2003$. Beetles were released within $0.5 \mathrm{~m}$ of the point of capture.

\section{Study species}

When the abundance of a species was consistently sufficiently large on a bar in each sampling period $(\mathrm{N}>50)$, it was possible to analyse temporal change in distribution. This was done for the carabids $B$. atrocaeruleum and B. decorum (Zenker in Panzer, 1800), and the elaterid Zorochros minimus (Boisduval \& Lacordaire, 1835). Additional analyses of total counts over all sampling periods were implemented for these species and the following less abundant species: the carabids, Clivina collaris (Herbst, 1784), Bembidion punctulatum Drapiez, 1821, and the elaterid, Fleutiauxellus maritimus (Curtis, 1840). This was similar to the method used by Holland et al. (1999) to measure "activity", except that because individuals could potentially be captured more than once, activity might be over-estimated by grouped counts. Grouped data are instead an indication of the spatial range of activity, rather than activity per se.

\section{SADIE analyses}

The SADIE method allows the visualisation and quantification of how much counts at each sampling unit contribute towards overall clustering, and the comparison of the spatial distribution of different data sets sampled at the same locations (Perry, 1995; Perry et al., 1999; Perry \& Dixon, 2002). The method relies on the concept of 'distance to regularity' which, conceptually, is the smallest possible total distance that individuals must move so that each sampling unit has the same number of individuals in it. The strength (magnitude and distance) of outflows and inflows during this transfer of individuals are calculated for each sampling point and compared with the average flow strength using Monte Carlo randomisations. This step calculates the local clustering indices $v_{i}$ and $v_{j}$, which indicate the amount an individual sample point contributes to clustering into a patch or gap respectively. The local clustering of patches and gaps do not always coincide with local counts because distance as well as magnitude are used to calculate outflows and inflows when determining local clustering, so whether a sampling point is part of a patch or a gap is also dependent on counts in nearby sampling points. The SADIE method therefore encapsulates spatial, rather than purely numeric information. The mean values of all outflows $\left(\bar{v}_{i}\right)$ and inflows $\left(\bar{v}_{j}\right)$ and their associated probabilities of departure from randomness indicate whether the overall distribution can be considered significantly non-random. These local and overall clustering indices were used to test for significant patterns in species and rarity distribution.

The overall spatial association $(X)$ is the correlation coefficient between the local clustering indices of two data sets and is used to test their overall association. Randomisations are used to 
TABLE 2. Summary inter-period stability of all possible SADIE spatial associations for Bembidion atrocaeruleum, B. decorum and Zorochros minimus. The total number of positive and negative associations, number of significant associations (bracketed and in bold), and significance levels of the associations $(*=5 \%, * *=1 \%$, and $* * *=0.1 \%)$ are all shown.

\begin{tabular}{lccc}
\hline & Bar & Positive associations & Negative associations \\
\hline B. atrocaeruleum & 1 & $11(\mathbf{4})$ & $4(\mathbf{1})$ \\
$(24 / 6,29 / 6,4 / 7,23 / 7,28 / 7,2 / 8 / 03)$ & & $*=2, * *=2)$ & $(*=1)$ \\
$\begin{array}{l}\text { B. atrocaeruleum } \\
(24 / 6,29 / 6,4 / 7,23 / 7,28 / 7,2 / 8 / 03)\end{array}$ & 2 & $15(\mathbf{1 4})$ & - \\
B. atrocaeruleum & 3 & $(*=2, * *=6, * * *=5)$ & 0 \\
$(24 / 6,29 / 6,4 / 7,23 / 7,28 / 7,2 / 8 / 03)$ & & $14(\mathbf{7})$ & - \\
B. decorum & 3 & $(*=3, * *=1, * * *=3)$ & - \\
$(24 / 6,29 / 6,4 / 7,23 / 7,28 / 7,2 / 8 / 03)$ & & $15(\mathbf{1 5})$ & 0 \\
$\begin{array}{l}\text { Z. minimus } \\
(24 / 6,29 / 6,4 / 7,23 / 7,28 / 7,2 / 8 / 03)\end{array}$ & 1 & $(* * *=15)$ & - \\
$Z$. minimus & 2 & 3 & 0 \\
$(23 / 7,28 / 7,2 / 8 / 03)$ & & - & - \\
$Z$. minimus & 3 & $(* * *=3)$ & - \\
$(23 / 7,28 / 7,2 / 8 / 03)$ & & & - \\
\hline
\end{tabular}

test the statistical probability that $X$ is significantly non-random $\left(P_{X}\right)$, regulating for the effects of autocorrelation using Dutilleul adjustments (Clifford et al., 1989; Dutilleul, 1993) of sample size. The overall spatial association index was used to: (1) test for significant differences in the inter-period distribution of a species, therefore testing the temporal stability of a species' microspatial distribution, (2) to test for associations between species distributions and environmental variation, and (3) to determine the degree of spatial association between species. All analyses used the parametric SADIE method, with the maximum number of randomisations (5967 for analysis of spatial distribution, and 9999 for tests of association) and met the recommendation of Holland et al. (1999) of containing at least 36 units (Table 1).

\section{RESULTS}

\section{Stability and patterns of spatial zonation}

Table 2 summarises SADIE spatial associations between sampling periods for $B$. atrocaeruleum, $B$. decorum and Z. minimus for each of the study patches when there were sufficient data. The overall distribution of each species was remarkably stable, as shown by the number of significant positive spatial associations. The only exception to this general pattern was B. atrocaeruleum on Bar 1, which showed less stability, as shown by the low number of significant positive associations and one significant negative association.

The microspatial distribution of species grouped across all sample dates are shown for Bar 1 and 3 in Fig. 3 and 4 respectively. All of the distributions on these two bars showed statistically significant patchiness. On Bar 1 (Fig. 3) there was clear evidence of spatial zonation in the species distributions, with $Z$. minimus and $C$. collaris situated in the "upper" more elevated section of the patch, $B$. decorum and B. punctulatum situated in the "lower" section of the patch very close to the water's edge, and Fleutiauxellus maritimus and B. atrocaeruleum situated in the "mid" section of the bar. The pattern of zonation was different on Bar 3 (Figs 1 and 4), with Z. minimus and $B$. atrocaeruleum generally distributed in an upstream area of the patch, $F$. maritimus tightly distributed in one small patch away from the main channel edge, and $B$. decorum mainly distributed on the main channel edge.

\section{Spatial association with environmental variation}

Significant positive and negative spatial associations between environmental variables complicated the interpretation of the spatial association between species distributions and environmental variables. Elevation and "distance from water" were significantly positively associated on all bars as might be expected. On Bar 1, elevation and vegetation cover were strongly negatively associated $\left(X=-0.51^{* * *}\right)$, as were "distance from water" and vegetation cover $(X=-0.39 * *)$. On Bar 2, however, vegetation cover was positively associated with elevation $(X=0.32 *)$, and on Bar 3 vegetation cover was negatively associated with "distance from water" $(X=$ $\left.-0.41^{* *}\right)$. On Bar 2 sediment size was found to be positively associated with both elevation $\left(X=0.33^{*}\right)$ and vegetation cover $\left(X=0.38^{*}\right)$.

Table 3 shows the spatial associations between the abundant species, and elevation, "distance from water", vegetation cover and sediment size. Bembidion atrocaeruleum was generally negatively associated with "distance from water" and positively associated with vegetation cover on each bar, although this was not always significant. Bembidion decorum showed much less consistent patterns of association, for example, its strong negative and positive associations with vegetation cover, although it was quite consistently negatively associated with elevation (Table 3 ).

Bembidion punctulatum was consistently and strongly negatively associated with elevation and "distance from water" and strongly negatively associated with sediment size on Bar 2. It was positively associated with vegetation cover on Bar 1. Clivina collaris was strongly positively associated with elevation and "distance from water" on Bar 1. Fleutiauxellus maritimus showed a strong positive 


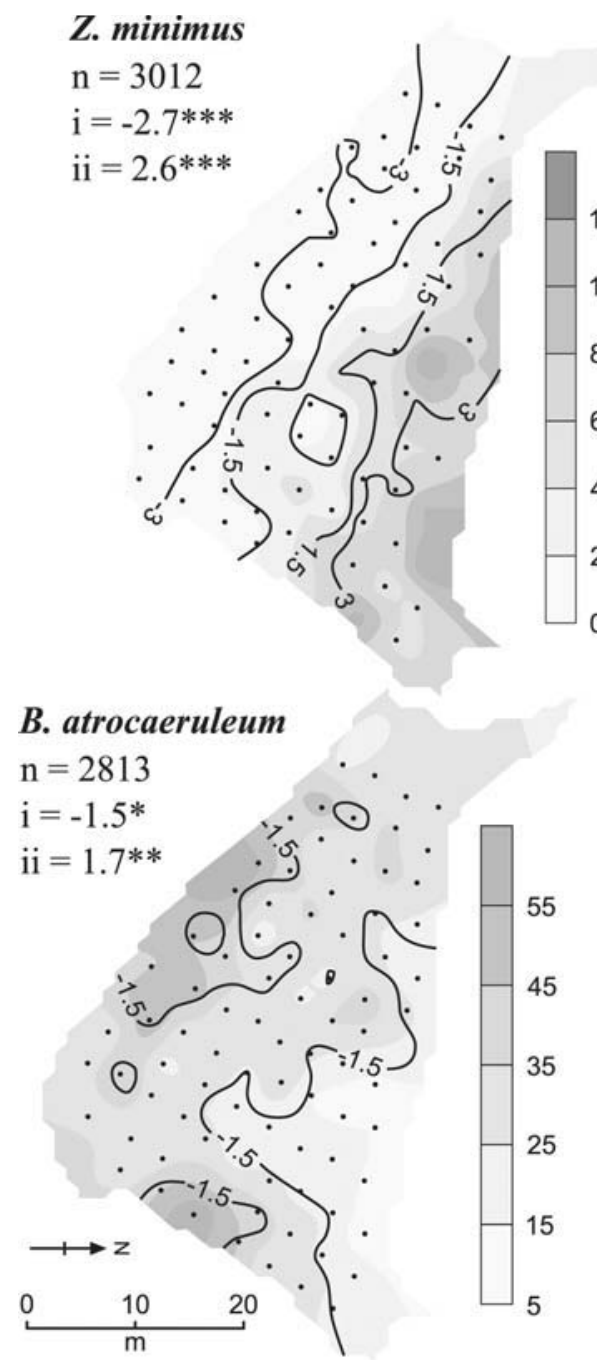

\section{C. collaris}

$\mathrm{n}=177$

$\mathrm{i}=-2.0^{* * *}$

ii $=1.8 * * *$

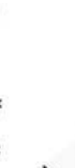

$\checkmark$<smiles>O=C1CCCCC1CCCO</smiles>

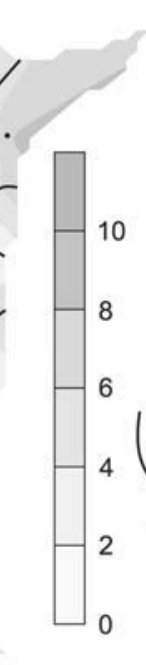

\section{F. maritimus}

$\mathrm{n}=108$

$\mathrm{i}=-2.1 * *$

ii $=2.2 * * *$

\section{B. punctulatum}

$\mathrm{n}=169$

$\mathrm{i}=-2.0 * * *$

ii $=2.1 * * *$

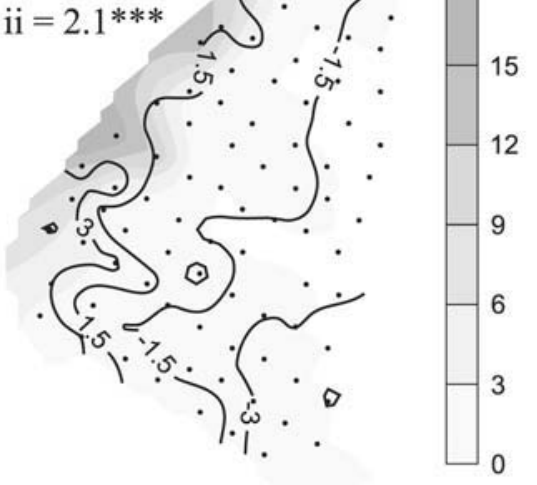

\section{B. decorum}

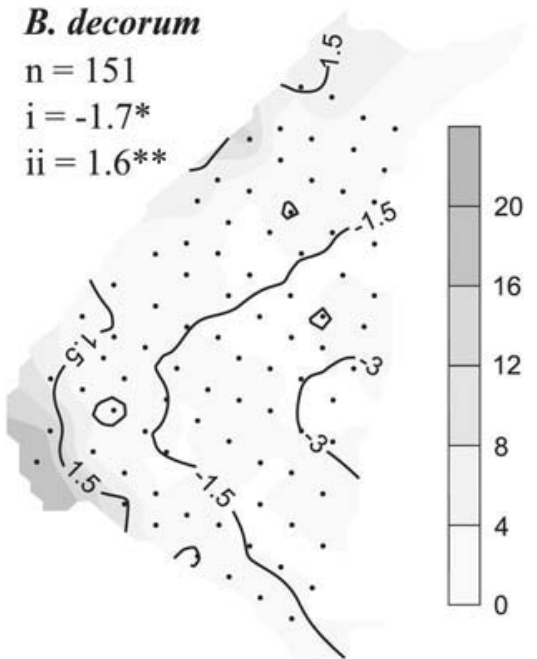

Fig. 3. The distribution and local clustering of Z. minimus, C. collaris, F. maritimus, B. atrocaeruleum, B. punctulatum, and B. decorum across all sampling dates on Bar 1 . The shading represents the interpolated numbers captured (note different scales); and the contours represent interpolated SADIE local clustering indices $\left(v_{i}\right.$ and $\left.v_{j}\right)$, where strong clustering into patches is indicated by areas $>1.5$, and strong clustering into gaps is indicated by areas $<-1.5$ (Holland et al., 1999). Traps are shown with black dots. The number of individual captures (n) is shown, together with (i) the mean standardised clustering indices over inflows $\left(\bar{v}_{i}\right)$ and (ii) outflows $\left(\bar{v}_{j}\right)$ which summarise overall clustering into gaps, and patches respectively (statistical significance is shown by $*=5 \%$, $* *=$ $1 \%, * * *=0.1 \%$ and ${ }^{\mathrm{NS}}=$ not significant).

association with "distance from water" and a strong negative association with vegetation on Bar 3. Zorochros minimus was strongly positively associated with elevation and "distance from water" on Bars 1 and 3, and was positively associated with vegetation cover on Bar 3 (Table 3).

\section{Spatial association between species}

Table 4 shows the spatial associations between all abundant species across the whole sampling period. These species could be roughly separated into three groups according to their level of spatial association or disassociation. The first was composed of $B$. atrocaeruleum, B. decorum, and B. punctulatum, which, although not always significantly associated, were never significantly disassociated. These species were generally distributed together in the "low" to "middle" sections of the ERS patches (there was no "upper", elevated section on Bar 3).

The second group comprised $Z$. minimus and $C$. collaris, which were distributed in the "mid" to "upper" sections of the ERS patches and were always significantly disassociated with group one species, with the exception of $B$. atrocaeruleum and Z. minimus on Bar 2 (where the relationship was not significant) and Bar 3 (where the relationship was significantly positive). Fleutiauxellus maritimus had a different kind of distribution to both group one and two species and was situated within the "mid" sections of the bars. It was not consistently associated with group one species and was always disassociated with group two species, although rarely significantly so (Table 4). 
TABLE 3. SADIE spatial associations $(X)$ between species on individual dates $(24 / 6 / 2003,29 / 6 / 2003,4 / 7 / 2003,23 / 7 / 2003$, 28/7/2003, 2/8/2003), or across all dates (-), and measured environmental variables. The Dutilleul adjusted, two-tailed, statistical significance $\left(P_{X}\right)$ of the associations is shown at the 5,1 and $0.1 \%$ levels by $*, * *$, and ${ }^{* * *}$, respectively, non-significant associations are shown by ${ }^{\mathrm{NS}}$.

\begin{tabular}{|c|c|c|c|c|c|c|}
\hline & Date & Bar & Elevation & Distance from water & Vegetation cover & Sediment size \\
\hline B. atrocaeruleum & $24 / 06$ & 1 & $0.29 * *$ & $0.31 * *$ & $-0.16^{\mathrm{NS}}$ & - \\
\hline B. atrocaeruleum & $29 / 6$ & 1 & $-0.11^{\mathrm{NS}}$ & $-0.11^{\mathrm{NS}}$ & $0.01^{\mathrm{NS}}$ & - \\
\hline B. atrocaeruleum & $4 / 7$ & 1 & $-0.26 * *$ & $-0.25 *$ & $0.18^{\mathrm{NS}}$ & - \\
\hline B. atrocaeruleum & $23 / 7$ & 1 & $-\mathbf{0 . 0 5} 5^{\mathrm{NS}}$ & $-0.06^{\mathrm{NS}}$ & $0.00^{\mathrm{NS}}$ & - \\
\hline B. atrocaeruleum & $28 / 7$ & 1 & $-0.67 * * *$ & $-0.57 * * *$ & $0.33 * *$ & - \\
\hline \multirow{2}{*}{ B. atrocaeruleum } & $2 / 8$ & 1 & $-0.41 * * *$ & $-0.31 * *$ & $0.22 *$ & - \\
\hline & - & 1 & $-0.44 * * *$ & $-0.46 * * *$ & $0.23^{\mathrm{NS}}$ & - \\
\hline \multirow[t]{2}{*}{ B. atrocaeruleum } & - & 2 & $-0.11^{\mathrm{NS}}$ & $-0.38 * *$ & $0.57 * * *$ & $0.27^{\mathrm{NS}}$ \\
\hline & - & 3 & $0.22^{\mathrm{NS}}$ & $-0.35 * *$ & $0.91 * * *$ & - \\
\hline B. decorum & $24 / 06$ & 3 & $-0.14^{\mathrm{NS}}$ & $0.27^{\mathrm{NS}}$ & $-0.35^{*}$ & - \\
\hline B. decorum & $29 / 6$ & 3 & $-0.33 * *$ & $0.31 *$ & $-0.56 * * *$ & - \\
\hline B. decorum & $4 / 7$ & 3 & $-0.44 * * *$ & $0.00^{\mathrm{NS}}$ & $-0.41 * *$ & - \\
\hline B. decorum & $23 / 7$ & 3 & $-0.16^{\mathrm{NS}}$ & $-0.31 *$ & $0.43 * * *$ & - \\
\hline B. decorum & $28 / 7$ & 3 & $0.09^{\mathrm{NS}}$ & $0.31 *$ & $-0.13^{\mathrm{NS}}$ & - \\
\hline B. decorum & $2 / 8$ & 3 & $0.03^{\mathrm{NS}}$ & $0.19^{\mathrm{NS}}$ & $-0.34 *$ & - \\
\hline \multirow[t]{2}{*}{ B. decorum } & - & 1 & $-0.73 * * *$ & $-0.68 * * *$ & $0.38^{* * *}$ & - \\
\hline & - & 3 & $-0.17^{\mathrm{NS}}$ & $0.31^{*}$ & $-0.20^{\mathrm{NS}}$ & - \\
\hline \multirow{2}{*}{ B. punctulatum } & -1 & - & $-0.54 * * *$ & $-0.42 * * *$ & $0.21^{*}$ & \\
\hline & -2 & - & $-0.69 * * *$ & $-0.74 * * *$ & $0.17^{\mathrm{NS}}$ & $-0.46 * * *$ \\
\hline C. collaris & -1 & - & $0.40^{* * *}$ & $0.41 * * *$ & $-0.05^{\mathrm{NS}}$ & - \\
\hline \multirow{3}{*}{ F. maritimus } & -1 & - & $-0.02^{\mathrm{NS}}$ & $0.10^{\mathrm{NS}}$ & $-0.18^{\mathrm{NS}}$ & - \\
\hline & -3 & - & $0.25^{\mathrm{NS}}$ & $0.58 * * *$ & $-0.48 * * *$ & - \\
\hline & -1 & - & $0.52 * * *$ & $0.40 * * *$ & $-0.07^{\mathrm{NS}}$ & - \\
\hline \multirow[t]{2}{*}{ Z. minimus } & -2 & - & $0.45^{* * *}$ & $0.59^{* * *}$ & $0.04^{\mathrm{NS}}$ & $-0.02^{\mathrm{NS}}$ \\
\hline & -3 & - & $0.22^{\mathrm{NS}}$ & $-0.21^{\mathrm{NS}}$ & $0.78 * * *$ & - \\
\hline
\end{tabular}

\section{DISCUSSION}

\section{Stability and patterns of spatial zonation}

Beetles are known to alter their microspatial distribution in response to changing soil moisture conditions (Antvogel \& Bonn, 2001), and ERS specialist beetles will move ahead of rising water levels in order to avoid immersion (Andersen, 1968). Given the rapid change in surface temperature and humidity in ERS habitats due to changes in weather (Desender, 1989), and the observed variation in weather and flow level between sampling periods (Fig. 2), the general temporal stability of the observed zonation was perhaps surprising. For example, between 24-26/7/2003, rising water levels nearly completely inundated Bar 3 and the distribution of species would have almost certainly changed during this event. However, any such microspatial redistribution was highly transitory, with rapid re-establishment of the "typical" microspatial distribution after water levels dropped on the following day of sampling. Andersen (1969) similarly observed a high degree of stability in the microhabitat choice of ERS specialist beetles across different weather conditions, seasons and geographical position. This stability suggests that the physical or biotic factors driving the spatial zonation of ERS beetles are strong and temporally robust.

All species showed strong patterns of microspatial zonation across all bars, which were generally highly sig- nificant. These patterns varied between the different bars and this was probably mainly due to variation in their elevation. Bars 1 and 2 were more elevated, with clear patterns of rising elevation with increasing lateral distance from the water, and Bar 3 was a mid-channel, low-lying bar, which did not have this clear lateral elevational gradient. There was a strong pattern of lateral zonation of species distribution on Bars 1 and 2, with certain species (e.g. B. decorum and B. punctulatum) distributed towards the "lower" section of the bars, some species distributed in the "mid" section of bars (e.g. F. maritimus and to a lesser extent $B$. atrocaeruleum), and some species distributed in the "upper" section of bars (e.g. C. collaris and $Z$. minimus). Desender (1989) found that B. atrocaeruleum, $B$. decorum and B. punctulatum had very similar distributions to those in this study in a spatially remote river system.

\section{Spatial association with environmental variation and inter-specifics}

The tests of spatial association between species distributions and environmental variation showed that the two descriptors of lateral gradient, elevation and "distance from water", were the most consistent explanatory variables. On Bars 1 and 2 the overall distribution of each species was significantly associated or disassociated with one or other (usually both) of these two environmental variables, with the exception of $F$. maritimus, which was 

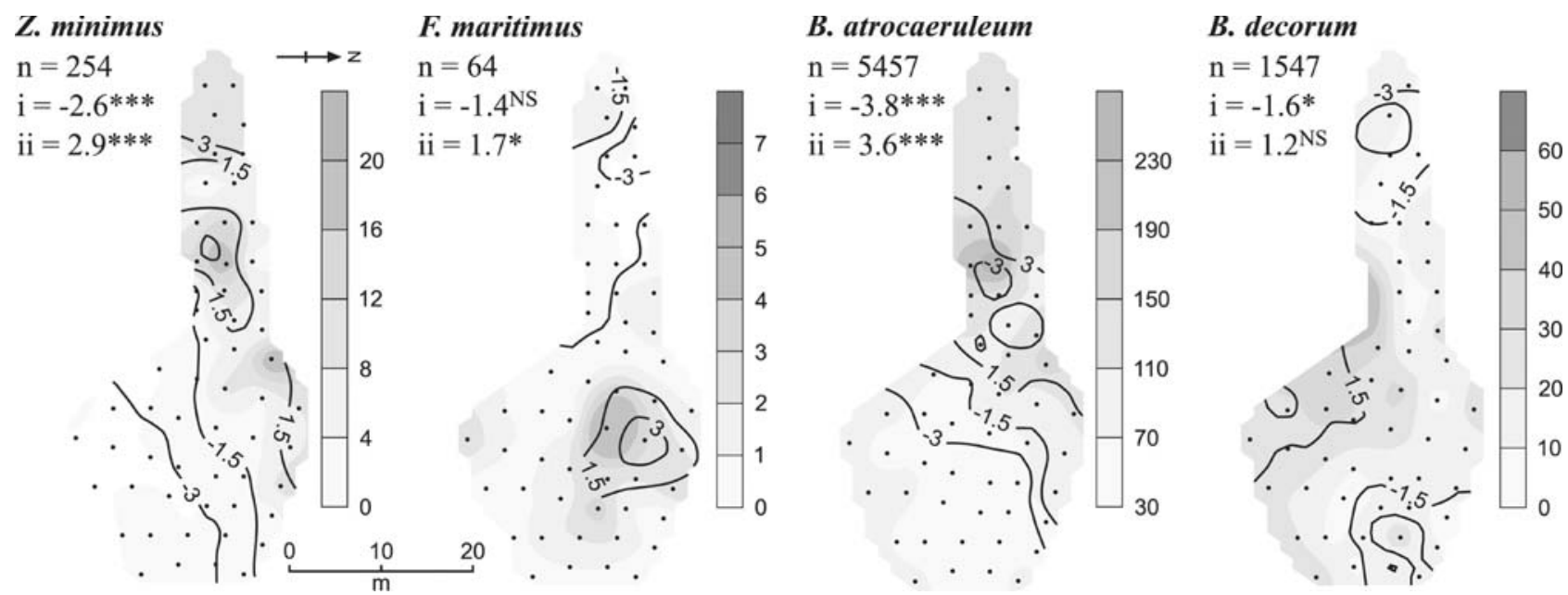

Fig. 4. The distribution and local clustering of Z. minimus, F. maritimus, B. atrocaeruleum, and B. decorum across all sampling dates on Bar 3 (see Fig. 3 for description).

associated with the "mid" section of Bar 1, and therefore did not show a linear response.

The spatial co-variation between vegetation cover and the lateral gradient would make interpretation of species' association or disassociation with vegetation cover difficult if it were not for the fact that the direction of the covariation was opposite between Bar 1 and 2. This lack of consistent spatial association with the distribution of any species across these two bars suggested that vegetation

TABLE 4. SADIE spatial associations between the distributions of species across the whole sampling period on Bars 1, 2 and 3 (see Table 3 for description).

\begin{tabular}{|c|c|c|}
\hline & Bar & Association \\
\hline B. atrocaeruleum - B. decorum & $\begin{array}{l}1 \\
3\end{array}$ & $\begin{array}{c}0.41^{* * *} \\
-\mathbf{0 . 2 3}^{\mathrm{NS}}\end{array}$ \\
\hline B. atrocaeruleum - B. punctulatum & $\begin{array}{l}1 \\
2\end{array}$ & $\begin{array}{l}0.44^{* * *} \\
0.10^{\mathrm{NS}}\end{array}$ \\
\hline B. atrocaeruleum -C. collaris & 1 & $-0.26 *$ \\
\hline B. atrocaeruleum - F. maritimus & $\begin{array}{l}1 \\
3\end{array}$ & $\begin{array}{r}0.41 * * * \\
-\mathbf{0 . 4 4}\end{array}$ \\
\hline B. atrocaeruleum - Z. minimus & $\begin{array}{l}1 \\
2 \\
3\end{array}$ & $\begin{array}{l}-\mathbf{0 . 5 0} * * * \\
-\mathbf{0 . 2 1} 1^{\mathrm{NS}} \\
0.82^{* * *}\end{array}$ \\
\hline B. decorum - B. punctulatum & 1 & $0.68 * * *$ \\
\hline B. decorum - C. collaris & 1 & $-0.40 * * *$ \\
\hline B. decorum - F. maritimus & $\begin{array}{l}1 \\
3\end{array}$ & $\begin{array}{l}0.18^{\mathrm{NS}} \\
0.13^{\mathrm{NS}}\end{array}$ \\
\hline B. decorum - Z. minimus & $\begin{array}{l}1 \\
3\end{array}$ & $\begin{array}{l}-0.63^{* * *} \\
-0.37^{*}\end{array}$ \\
\hline B. punctulatum - C. collaris & 1 & $-0.39 * * *$ \\
\hline B. punctulatum - F. maritimus & 1 & $0.40 * * *$ \\
\hline B. punctulatum - Z. minimus & $\begin{array}{l}1 \\
2\end{array}$ & $\begin{array}{l}-0.79 * * * \\
-0.55^{* * *}\end{array}$ \\
\hline C. collaris $-F$. maritimus & 1 & $-0.20^{\mathrm{NS}}$ \\
\hline C. collaris - Z. minimus & 1 & $0.58 * * *$ \\
\hline F. maritimus - Z. minimus & $\begin{array}{l}1 \\
3 \\
\end{array}$ & $\begin{array}{l}-0.51^{* * *} \\
-0.23^{\mathrm{NS}}\end{array}$ \\
\hline
\end{tabular}

cover was not influencing the distribution of species on Bars 1 and 2. Clear zones of different sediment size were only present on Bar 2, on which B. punctulatum was found to be significantly positively associated with the distribution of finer sediment. The distribution of the different sediment zones did co-vary with the distribution of both elevation and vegetation cover, but Desender (1989) also reported that $B$. punctulatum was spatially associated with fine sediments.

On Bar 3 there were no consistent spatial associations with elevation for any species, and the significant associations with "distance from water" were not consistent with those observed for Bars 1 and 2. The relatively low elevation of this bar, combined with its unusual shape, meant that species were distributed in a less regular fashion and were potentially responding to factors other than lateral gradient. The limited elevation, and consequent increased humidity, of this bar might explain why B. decorum, which is usually distributed along the water's edge of more elevated bars, had a wider spatial range of distribution here. The positive associations between B. atrocaeruleum and $Z$. minimus and vegetation cover were the strongest spatial associations observed for any environmental variable in the investigation, $X=0.91$ and 0.78 respectively, which suggests that vegetation cover was important for these species on Bar 3. Vegetation cover is known to affect microclimate (Thiele, 1977), and can potentially provide food in the form of seeds, detritus, or invertebrate prey. However, there was little evidence that vegetation cover affected the distribution of these species on Bars 1 and 2. On stream edges vegetation might provide easy means of escape from rising water levels, or concentrated areas of food due to the "sieving" of drifting invertebrates and emergence of insects on stems, and this might explain this pattern for Bar 3 . Or it could be that vegetation cover is favourable for $B$. atrocaeruleum, but that it was not able to utilise it on Bars 1 and 2 because of low humidity levels. Without direct evidence for these possibilities, this is open to conjecture. 
An alternative explanation for the zonation of species on ERS relates to the possibility of competitive interactions between species (c.f. Spence, 1979). Andersen (1988), after more than 20 years studying the ecology of riparian and ERS specialist species of Bembidion, concluded that the microspatial segregation of these cogenerics was mainly related to differences in their preference for, and tolerance of, physical variables, and that there was only limited evidence for competitive interactions between some species. Andersen's study was between co-generic species, and competitive interactions between beetle species that are more distantly related are likely to be even less probable due to the larger ecomorphological, physiological and behavioural separation between the species, and hence, ability to utilise different resources.

The distribution of species on Bar 3 provided a useful test of the competitive interaction possibility in the absence of a distinct lateral gradient in environmental variation that seemed to structure the assemblages on Bars 1 and 2. On Bar 3, B. atrocaeruleum and Z. minimus were found to be very strongly positively associated with one another, in strong contrast to the situation on Bars 1 and 2. This suggested that these two distantly related species were not competing with one another. Closely related species such as B. decorum and B. punctulatum would be more likely to demonstrate competitive interactions. However, Desender (1989) suggested that these species were associated with different sediment sizes, and there was some evidence for this in the current investigation also. In summary therefore, there was little evidence to suggest that competitive interactions were producing the inter-specific microspatial zonation.

\section{Implications}

Our research at the microscale supports the findings of Sadler et al. (2004) at a larger scale; that species are associated with distinct microhabitats and that greater microhabitat heterogeneity induces greater diversity of ERS beetles. Species distributions were mainly related to lateral environmental gradients, rather than visibly distinct microhabitats (e.g. patches of differently sized sediment). Therefore, larger ERS bars will have longer lateral environmental gradients and will probably support more species, each favouring different conditions along the gradient. Furthermore, larger bars will preserve a longer lateral gradient of conditions under a range of flow levels, whereas the lateral gradient of small, less elevated bars will contract more quickly as water level rises. Therefore, any operation that reduces ERS microhabitat diversity or the size of ERS bars, such as river channelisation, aggregate extraction or regulation is likely to negatively impact ERS invertebrate diversity.

ACKNOWLEDGEMENTS. We thank the Department of Geography, Earth and Environmental Sciences at the University of Birmingham and the Countryside Council for Wales for funding; A. Jones (Environment Agency) for obtaining landowner contact details; T. Kinsey, G. Trow and D. Davies for access permission; C. Butcher, R. Johnson and A. Hewertson for help with fieldwork and equipment preparation; and the British
Atmospheric Data Centre and the Environment Agency for access to the Meteorological Office Land Surface Observation Stations Data and stage data respectively.

\section{REFERENCES}

ANDERSEN J. 1968: The effect of inundation and choice of hibernation sites of Coleoptera living on river banks. Norsk Entomol. Tidsskr. 15: 115-133.

AnDERSEn J. 1969: Habitat choice and life history of Bembidiini (Col., Carabidae) on river banks in central and northern Norway. Norsk Entomol. Tidsskr. 17: 17-65.

ANDERSEN J. 1978: The influence of the substratum on the habitat selection of Bembidiini (Col., Carabidae). Norw. J. Entomol. 25: 119-138.

ANDERSEN J. 1983: The habitat distribution of species of the tribe Bembidini (Coleoptera, Carabidae) on banks and shores in northern Norway. Notul. Entomol. 63: 131-142.

ANDERSEN J. 1985: Low thigmo-kinesis, a key mechanism in habitat selection by riparian Bembidion (Carabidae) species. Oikos 44: 499-505.

ANDERSEN J. 1988: Resource partitioning and interspecific interactions among riparian Bembidion species (Coleoptera: Carabidae). Entomol. Gen. 13: 47-60.

ANDERSEN J. 1989: Photoresponse of carabid beetles depends on experimental design. Oikos 54: 195-200.

Antvogel H. \& BonN A. 2001: Environmental parameters and microspatial distribution of insects: a case study of carabids in an alluvial forest. Ecography 24: 470-482.

Bates A.J., Sadler J.P., Fowles A.P. \& Butcher C.R. 2005: Spatial dynamics of beetles living on exposed riverine sediments in the Upper River Severn: Method development and preliminary results. Aquat. Cons. 15: 159-174.

Bates A.J., Sadler J.P. \& Fowles A.P. 2006: Conditiondependent dispersal of a patchily distributed riparian ground beetle in response to disturbance. Oecologia 150: 50-60.

BonN A. \& KLEINwÄChTER M. 1999: Microhabitat distribution of spider and ground beetle assemblages (Araneae, Carabidae) on frequently inundated river banks of the River Elbe. $Z$. Ökol. Natursch. 8: 109-123.

ChURCh M. 1983: Pattern of instability in a wandering gravel bed channel. In Collison J.D. \& Lewin J. (eds): Modern and Ancient Fluvial Systems. International Association of Sedimentologists Special Publications 6. pp. 169-180.

Clifford P., Richardson S. \& HÉmon D. 1989: Assessing the significance of the correlation between two spatial processes. Biometrics 45: 123-134.

Colombini I., Chelazzi L., Fallaci M. \& Palesse L. 1994: Zonation and surface activity of some Tenebrionid beetles living on a Mediterranean sandy beach. J. Arid Environ. 28: 215-230.

DESENDER K. 1989: Ecomorphological adaptations of riparian carabid beetles. In Wouters K. \& Baert L. (eds): Comptes Rendus du Symposium "Invertèbres de Belgique". Royal Institute of Natural Sciences, Brussels, pp. 309-314.

Dungan J.L., Perry J.N., Dale M.R.T., Legendre P., CitronPousty S., Fortin M.-J., Jakomulska A., Miriti M. \& RosenBERG M.S. 2002: A balanced view of scale in spatial statistical analysis. Ecography 25: 626-640.

Dutilleul P. 1993: Modifying the $t$-test for assessing the correlation between two spatial processes. Biometrics 49: 305-314.

Gereben B.-A. 1995: Co-occurrence and microhabitat distribution of six Nebria species (Coleoptera: Carabidae) in an alpine glacier retreat zone in the Alps, Austria. Arctic Alpine Res. 27: 371-379. 
Hassell M.P. \& Southwood T.R.E. 1978: Foraging strategies of insects. Annu. Rev. Ecol. Syst. 9: 75-98.

Hastings A. 1987: Can competition be detected using species co-occurrence data? Ecology 68: 117-123.

Holland J.M., Perry J.N. \& Winder L. 1999: The within-field spatial and temporal distribution of arthropods in winter wheat. Bull. Entomol. Res. 89: 499-513.

LEVIN S.A. 1992: The problem of pattern and scale in ecology: The Robert H. MacArthur award lecture. Ecology 73: 1943-1967.

NIEMELÄ J. 1993: Interspecific competition in ground-beetle assemblages (Carabidae): What have we learned? Oikos 66: 325-335.

OtTESEN P.S. 1996: Niche segregation of terrestrial alpine beetles (Coleoptera) in relation to environmental gradients and phenology. J. Biogeogr. 23: 353-369.

Paetzold A., Schubert C.J. \& Tockner K. 2005: Aquaticterrestrial linkages along a braided-river: Riparian arthropods feeding on aquatic insects. Ecosystems 8: 748-759.

Perry J.N. 1995: Spatial analysis by distance indices. J. Anim. Ecol. 64: 303-314.

Perry J.N., Winder L., Holland J.M. \& Alston R.D. 1999: Red-blue plots for detecting clusters in count data. Ecol. Lett. 2: $106-113$.

Perry J.N. \& Dixon P.M. 2002: A new method to measure spatial association for ecological count data. Ecoscience 9: $133-141$.
Petts G.E., Gurnell A.M., Gerrard A.J., Hannah D.M., Hansford B., Morrissey I., Edwards P.J., Kollmann J., Ward J.V., TOCKNer K. \& SMith B.P.G. 2000: Longitudinal variations in exposed riverine sediments: a context for the ecology of the Fiume Tagliamento, Italy. Aquat. Cons. 10: 249-266.

SAdler J.P., Bell D. \& Fowles A.P. 2004: The hydroecological controls and conservation value of beetles on exposed riverine sediments in England and Wales. Biol. Conserv. 118: 41-56.

SPENCE J.R. 1979: Riparian carabid guilds - a spontaneous question generator. In Erwin T.L., Ball G.E., Whitehead D.R. \& Halpern A.L. (eds): Carabid Beetles: Their Evolution, Natural History and Classification. W. Junk, The Hague, pp. 525-537.

Thiele H.U. 1977: Carabid Beetles in their Environments: A Study on Habitat Selection by Adaptation. Springer, Berlin, New York, 369 pp.

WaLlin H. \& Еквом B. 1994: Influence of hunger level and prey densities on movement patterns in three species of Pterostichus beetles (Coleoptera: Carabidae). Environ. Entomol. 23: 1171-1181.

Ward J.V., Tockner K. \& Schiemer F. 1999: Biodiversity of floodplain ecosystems: ecotones and connectivity. Regul. River. 15: 125-139.

Received September 5, 2006; revised and accepted March 23, 2007 